\title{
Synthesis of Biodegradable Superabsorbent Polymers from Carboxymethyl Cellulose/Humic Acid
}

\author{
Nurul Ismillayli ${ }^{\star}$, Siti Raudhatul Kamali, Surya Hadi, Dhony Hermanto \\ Department of Chemistry, Faculty of Mathematics and Natural Science, University of Mataram. Jalan Majapahit No. \\ 62 Mataram 83125 Indonesia. \\ *Email: nurul.ismillayli@unram.ac.id
}

Received April 2019; Accepted Agustus 2019

\begin{abstract}
Superabsorbent polymer (SAP) blend has been synthesized from carboxymethyl cellulose (CMC), humic acid, and aluminum sulphate octadecahydrate cross-linker. SAP is hydrophilic networks that can absorb and retain huge amount of water within their structures. Humic acid as starting material of polymer, was isolated from subgrade Batujai Dam by using IHSS method. Water Absorption Capacity (WAC) measurement, FTIR analysis, and agitation tests to investigate the cross-linking process and which of $\mathrm{Al}^{3+}$ and $\mathrm{SO}_{4}{ }^{2-}$ ions causes the crosslinking are carried out. Optimum cross-linking ratio of CMC and cross-linker appeared to be $2 w t \%$ corresponded to WAC determination. FTIR spectrum of $\mathrm{CMC} /$ humic acid blend and agitation test showed that $\mathrm{CMC}$ react with humic acid during polymerization process via $\mathrm{Al}^{3+}$ ion.
\end{abstract}

Keywords: carboxymethyl cellulose; $\mathrm{Al}^{3+}$ ion; humic acid; superabsorbent polymer.

\section{INTRODUCTION}

Recently interest in developing superabsorbent from biopolymer such as starch [1], cellulose and its derivates [2], and chitosan [3] has been increased due to their exceptional properties compared to petroleum-based polymers that is sustainable, biocompatible, biodegradable, renewable and nontoxic [4]. Owing to their three-dimensional polymeric networks that can absorb and retain large volumes of water, superabsorbents are widely used in many fields, such as hygienic products, drugdelivery systems, agriculture and horticulture [5].

Superabsorbent prepared through electrostatic complexing can be used for example crosslinking of $\mathrm{CMC} / \mathrm{HEC}$ [2] and $\mathrm{CMC} /$ starch [1] with aluminium sulphate as cross-linking agents. Aluminium sulphate, with its cationic species in effective form of $\mathrm{Al}^{3+}, \mathrm{Al}(\mathrm{OH})^{2+}$ and oligomeric species in aqueous solution when $\mathrm{pH}<5$, provides multivalent positive charges and abundant sites for crosslinking with anionic groups [6] such us $\mathrm{NaCMC}$ that containing $\mathrm{COO}^{-}$groups to form hydrogel structures.

Application of humic acids (HA, one of the main fractions of humic substances) in agriculture as soil fertilizer and soil conditioner has been extensively discussed in the literature [7]. Containing of carboxylic and phenolic groups, humic acid provides favorable conditions for chemical reactions, biological activity and improves physical structure of soil, water holding capacity, $\mathrm{pH}$ buffering and accelerate transport of nutrients to plants [8]. Therefore, it was planned to synthesize a biodegradable superabsorbent with suitable for soil water conservation by crosslinking CMC and humic acid with aluminum ions. Optimum cross-linker concentration, water absorption capacity and FTIR analysis were also studied.

\section{EXPERIMENTAL SECTION}

\section{Materials}

Humic acid used in this study were isolated from subgrade Batujai Dam, Lombok Tengah, West Nusa Tenggara. Analytical quality materials (analytical grade) for humic acid isolation include: $\mathrm{NaOH}$ (sodium hydroxide), $\mathrm{HCl}$ (hydrogen chloride), $\mathrm{HF}$ (hydrogen fluoride), $\mathrm{AgNO}_{3}$ (silver nitrate), paper Whatman filter 42, $\mathrm{pH}$ indicator strip were obtained from Merck (Germany). Nitrogen gas, carboxymethyl cellulose sodium salt, aluminum sulphate octadecahydrate was used at reagent grade and could be available from commercial sources.

\section{Instrumentation}

Tomy LC-200 centrifuge, Memmert WNB 2214 shaker, BIOSAN/MSH 300 magnetic hot plate, Memmert u10 oven, Hanna pHmeter, Simadzu electrical balance, and Perkin Elmer Spectroscopy FTIR.

\section{Procedure}

Isolation and Characterization of Humic Acid

Humic acid isolated and purifed by using recommended method of the International Humic 
Substances Society [9]. Humic acid isolated then were characterized using FTIR spectroscopy.

\section{Preparation of Cross-Linked CMC/HA Blend}

Carboxymethyl cellulose sodium salt $(10 \mathrm{~g})$ was mixed with $1.0 \mathrm{~L}$ of distilled water (DW) in a large beaker using a magnetic stirrer. The solution was agitated for 1 hour at $70^{\circ} \mathrm{C}$. Then varying amounts of aluminum sulfate were added to the beaker to investigate the optimum crosslinkage, and the solution was allowed to mix for another $30 \mathrm{~min}$. The solution was then spread on Teflon baking pans and dried at $50^{\circ} \mathrm{C}$ until a film is formed. The film was shredded with a blender and then ground into a powder with a mortar and pestle. Dried film of the cross-linked CMC, was crushed and dissolved in DW. Using magnetic hot plate, humic acid solution mixed with the cross-linked CMC gelatinezed for 30 minute at $70^{\circ} \mathrm{C}$. Result paste was dried overnight at $50^{\circ} \mathrm{C}$, crushed, and tested.

\section{Investigation of the Active Ion}

When aluminum sulfate octadecahydrate dissolve in water, the material dissociates into $\mathrm{Al}^{3+}$ and $\mathrm{SO}_{4}{ }^{2-}$. Investigating the ions which enters the cross-linking reaction has done by adopting following procedure: pieces of the cross-linked $\mathrm{CMC} /$ starch blend immersed in hot water $70^{\circ} \mathrm{C}$ for 30 minutes and then filtered. The extraction then divided into two parts. The first part is tested for sulfate group using $\mathrm{BaCl}_{2}$ solution, while the second part is tested for $\mathrm{Al}^{3+}$ ion using $\mathrm{NaOH}$ solution.

\section{Water Absorption Capacity Measurement at Various Cross-linker Concentration}

The accurately weighed $\mathrm{CMC} / \mathrm{HA}$ superabsorbent powder in various amount of $\mathrm{Al}^{3+}$ $(0.1 \pm 0.0001 \mathrm{~g})$ was immersed in $500 \mathrm{~mL}$ DW for $2 \mathrm{~h}$ to reach swelling equilibrium. The swollen sample were then separated from the unabsorbed water by being filtered over 100-mesh nylon screen. The weight of the swollen sample was measured. The water absorption capacity (WAC) was calculated by the following equation,

$$
W_{A C}=\frac{W_{1}-W_{0}}{W_{0}}
$$

Where $W_{0}$ is dried sample weight $(g)$ and $W_{1}$ is swollen sample weight $(\mathrm{g})$ and $\mathrm{W}_{\mathrm{AC}}$ is water absorption capacity per gram of dried sample $(\mathrm{g} / \mathrm{g})$.

\section{RESULTS AND DISCUSSION}

\section{Isolation and Characterization of Humic Acid}

HA was obtained from subgrade Batujai Dam after separating its humin and fulvic acid then purifying by using mixed $\mathrm{HCl} / \mathrm{HF}$ solution to dissolves silica oxide mineral. Based on interpretation of the FTIR spectra of crude and pure HA in Table 1 can be seen that purification decreased the ash content, from $5.3 \%$ to $1.3 \%$, indicated by decrease of $\mathrm{SiO}$ stretching in $914 \mathrm{~cm}^{-1}$. Peak at $1388 \mathrm{~cm}^{-1}$ coupled with $1659 \mathrm{~cm}^{-1}$ peak suggests that crude HA has carboxylate groups, presumably because of the ash content [10][11]. The peak was shifted to 1381 and $1653 \mathrm{~cm}^{-1}$ respectively after purification of HA. Intensity of this peak was decreased, while peak intensity around $1722 \mathrm{~cm}^{-1}$ increased at pure HA spectra due to carboxylate to carboxylic changes in HA. This is supported by result of ash content determination that purification decreased ash content from $5.60 \%$ to $1.13 \%$. Based on FTIR spectra, HA isolated containing functional groups of $\mathrm{COOH}$, phenolic $-\mathrm{OH}$, aliphatic hydrocarbon and aromatic ring.

Table 1 Interpretation of the FTIR spectra of HA

\begin{tabular}{|c|c|c|}
\hline $\begin{array}{l}\text { HA before } \\
\text { purification }\left(\mathrm{cm}^{1}{ }^{1}\right)\end{array}$ & $\begin{array}{c}\text { HA after } \\
\text { purification } \\
\left(\mathrm{cm}^{-1}\right)\end{array}$ & Vibration Type \\
\hline 3425 & 3408 & $\mathrm{OH}$ stretching of alcohols or phenols \\
\hline 2927 & 2927 & asymmetric stretching of aliphatic $\mathrm{C}-\mathrm{H}$ in $-\mathrm{CH}_{2}$ - groups \\
\hline 2851 & 2851 & symmetric stretching of aliphatic $\mathrm{C}-\mathrm{H}$ in $-\mathrm{CH}_{2}$ - groups \\
\hline 1728 & 1722 & $\mathrm{C}=\mathrm{O}$ stretching (carboxylic and carbonyl group) \\
\hline 1659 & 1653 & $\begin{array}{l}\text { aromatic } \mathrm{C}=\mathrm{C} \text { and asymmetric } \mathrm{C}=\mathrm{O} \text { stretching in } \mathrm{COO}^{-} \\
\text {groups }\end{array}$ \\
\hline 1564 & 1552 & nitro groups \\
\hline 1463 & 1457 & methyl asymmetric $\mathrm{C}-\mathrm{H}$ bending \\
\hline 1388 & 1381 & $\begin{array}{l}\mathrm{OH} \text { deformation and } \mathrm{C}-\mathrm{O} \text { stretching in phenols and } \mathrm{COO}^{-} \\
\text {groups }\end{array}$ \\
\hline 1255 & 1236 & $\begin{array}{l}\mathrm{C}-\mathrm{O} \text { stretching of aryl ethers and } \mathrm{OH} \text { deformation of } \mathrm{COOH} \\
\text { groups }\end{array}$ \\
\hline 1035 & 1035 & C-O stretching (alcohols and polysaccharide) \\
\hline 914 & 914 & SiO stretching \\
\hline 700 & 700 & ortho disubstituted out-of-plane $=\mathrm{C}-\mathrm{H}$ bending vibration \\
\hline $529-473$ & $524-466$ & metal-humic acid interaction \\
\hline
\end{tabular}




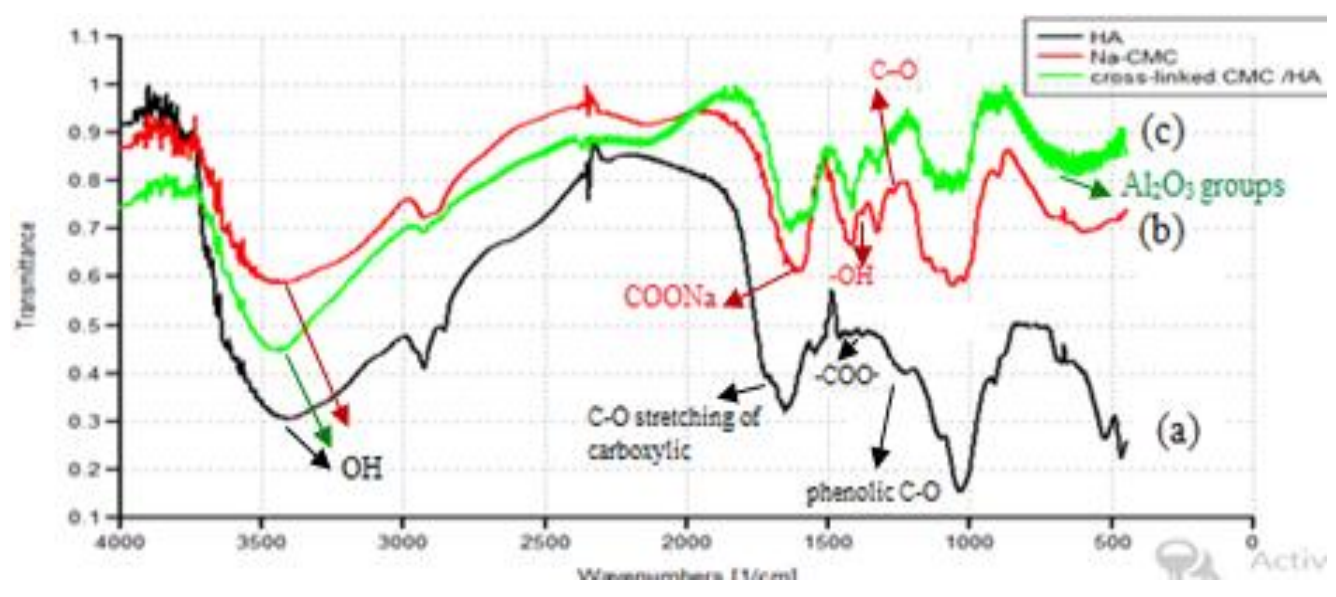

Figure $1 \mathrm{FTIR}$ spectra of), $\mathrm{CMC}$ (b), and $\mathrm{CMC} / \mathrm{HA}$ blend (c)

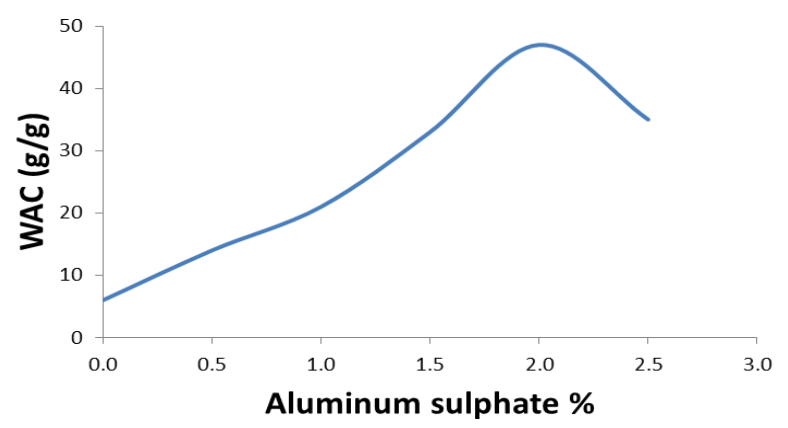

Figure 2 Optimum percent of aluminum sulphate octaadecahydrate cross-linker

\section{Proposed Interaction of cross-linked CMC/HA- $\mathrm{Al}^{3+}$}

The IR spectra of the HA, CMC, and CMC/HA blend are shown in Fig. $1(\mathrm{a}-\mathrm{C})$, respectively. Comparing with the IR spectrum of CMC (Fig. 1(b)), the absorption bands at $1608 \mathrm{~cm}^{-1}$ for the -COONa group shift to $1634 \mathrm{~cm}^{-1}$, and the absorption bands at $1381\left(\mathrm{OH}\right.$ bending vibration) and $1268 \mathrm{~cm}^{-1}(\mathrm{C}-\mathrm{O}$ $\mathrm{HA}$ (a stretching) disappeared in the IR spectrum of cross-linked CMC/HA (Fig. 1(c)). Comparing with the IR spectrum of HA (Fig. 1(a)), the absorption bands at 3413 and $1653 \mathrm{~cm}^{-1}$ for the $-\mathrm{OH}$ stretching of alcohols or phenols group and $\mathrm{C}=\mathrm{O}$ stretching in $\mathrm{COO}^{-}$groups shift to 3451 and $1634 \mathrm{~cm}^{-1}$ respectively and the absorption bands at $1722 \mathrm{~cm}^{-1}$ (C-O stretching of carboxylic group of $\mathrm{HA}$ ), $1381 \mathrm{~cm}^{-1}$ (-COO asymmetric stretching of $\mathrm{HA}$ ) and $1255 \mathrm{~cm}^{-1}$ (phenolic $\mathrm{C}-\mathrm{O}$ stretching of $\mathrm{HA}$ ) disappeared in the spectrum of cross-linked $\mathrm{CMC} / \mathrm{HA}$ superabsorbent (Fig. 1(c)). The results obtained from IR analysis showed that the reaction of both CMC and HA occurs in carboxylic and phenolic groups of HA and $\mathrm{COO}^{-}$groups of $\mathrm{CMC}$ via cross-linker.

\section{Investigation of the Active Ion}

In order to suggest a reasonable interaction, knowing which ions enters the cross-linking reaction $\left(\mathrm{Al}^{3+}\right.$ or $\mathrm{SO}_{4}^{2-}$ ) is needed. Tested for sulfate group using $\mathrm{BaCl}_{2}$ solution on extraction of cross-linked
$\mathrm{CMC} / \mathrm{HA}$, shows dense white precipitate indicated that the sulphate group not share for blend formation.While, tested for $\mathrm{Al}^{3+}$ ion using $\mathrm{NaOH}$ solution on extraction of cross-linked $\mathrm{CMC} / \mathrm{HA}$, shows the absence of $\mathrm{Al}^{+3}$ ion. It was confirmed with FTIR analysis that the $\mathrm{Al}^{3+}$ ion share in the blend structure as cross-linker that bind the carboxylic or phenolic groups of $\mathrm{HA}$ with - $\mathrm{COO}^{-}$groups of CMC.

Water Absorption Capacity Measurement at Various Cross-linker Concentration

The effect of the amount of $\mathrm{Al}^{3+}$ ion on WAC was shown in Fig. 2. The max. of absorbency was at $2 \%$ of $\mathrm{Al}^{3+}$ ion. Increasing cross-linker could increase the nodes of network and the cross-linker density, which is favorable to the super-absorbent absorbing and retaining fluid [12]. Low concentration of the cross-linker leads to low degree of cross linking, and it is hard for network structure to form, so the water absorbency is low. However, when it is higher than the best value, there are more cross-linking points and the pores become smaller in the network, which causes the macroscopic decrease of the absorbency [13].

\section{CONCLUSION}

A superabsorbent was successfully prepared using the cross-linking of $\mathrm{CMC} / \mathrm{HA}$ with aluminum ions. The interaction was occurs in carboxylic and 
phenolic groups of $\mathrm{HA}$ and - $\mathrm{COO}^{-}$groups of $\mathrm{CMC}$ via $\mathrm{Al}^{3+}$ ion as cross-linker. The mass ratio of $\mathrm{Al}^{3+}$ ion to $\mathrm{CMC}$ could affect its water absorption capacity.

\section{ACKNOWLEDGEMENTS}

This work was financially supported by DIPA BLU (PNBP) Universitas Mataram Project.

\section{References}

[1] Braihi, A. J., Salih, S. I., Hashem, F. A., \& Ahmed, J. K. (2014). Proposed cross-linking model for carboxymethyl cellulose/starch superabsorbent polymer blend. Int J Mater Sci Appl, 3, 363-369.

[2] Hakim, Y. Z., Yulizar, Y., Nurcahyo, A., \& Surya, M. (2018). Green Synthesis of Carbon Nanotubes from Coconut Shell Waste for the Adsorption of $\mathrm{Pb}$ (II) Ions. Acta Chimica Asiana, 1(1), 6-10.

[3] Ge, H., Hua, T., \& Chen, X. (2016). Selective adsorption of lead on grafted and crosslinked chitosan nanoparticles prepared by using $\mathrm{Pb} 2+$ as template. Journal of hazardous materials, 308, 225-232.

[4] Sadeghi, M., \& Yarahmadi, M. (2011). Synthesis and characterization of superabsorbent hydrogel based on chitosan-gpoly (acrylic acid-coacrylonitrile). African Journal of Biotechnology, 10(57), 1226512275.

[5] Nnadi, F., \& Brave, C. H. I. R. S. (2011). Environmentally friendly superabsorbent polymers for water conservation in agricultural lands. Journal of Soil Science and Environmental Management, 2(7), 206-211.

[6] Shuping, B., Chenyi, W., Qing, C., \& CAIHUA, Z. (2004). Studies on the mechanism of hydrolysis and polymerization of aluminum salts in aqueous solution: correlation between the "Core-links" model and "Cage-like" KegginAl13 model. Coordination Chemistry Reviews, 248(5-6), 441-455.

[7] Sanjaya, R. K., Ismillayli, N., \& Hermanto, D. (2019). An Amperometric Biosensor For Hg (II) Based On Urease/Alginate-Chitosan Membrane Modified Screen Printed Carbon Electrode. Jurnal Pijar Mipa, 14(3), 184-188.

[8] Ibrahim, S. M., El Fadl, F. I. A., \& El-Naggar, A. A. (2014). Preparation and characterization of crosslinked alginate-CMC beads for controlled release of nitrate salt. Journal of
Radioanalytical
Chemistry, 299(3), 1531-1537.

[9] International Humic Substances Society, 2008, http://www.ihss.gatech.edu

[10] Takács, M., \& Alberts, J. J. (1999). Changes in chemical composition, FTIR and fluorescence spectral characteristics of humic acids in peat profiles. In Understanding Humic Substances (pp. 169-177). Woodhead Publishing.

[11] Ismillayli, N., Santosa, S. J., \& Siswanta, D. (2015). Penerapan Freundlich Model Pada Adsorpsi-Reduktif Isotherm Aucl4- Dengan Asam. Jurnal Pijar Mipa, 10(2).

[12] Pourjavadi, A., \& Mahdavinia, G. R. (2006). Superabsorbency, $\mathrm{pH}$-sensitivity and swelling kinetics of partially hydrolyzed chitosan-g-poly (acrylamide) hydrogels. Turkish Journal of Chemistry, 30(5), 595-608.

[13] Ma, Z., Li, Q., Yue, Q., Gao, B., Xu, X., \& Zhong, Q. (2011). Synthesis and characterization of a novel super-absorbent based on wheat straw. Bioresource technology, 102(3), 2853-2858. 